\title{
O Partido Democrático Paranaense de 1927 a 1930: um estudo dos capitais familiares e sociais de seus dirigentes
}

\author{
Natália Cristina Granato ${ }^{1}$
}

\begin{abstract}
Resumo: Este trabalho objetiva mapear um perfil genealógico e social dos dirigentes do Partido Democrático no Paraná. Tal agremiação surgiu no estado de São Paulo e posteriormente se espalhou por outros estados da federação no contexto da Primeira República ou "República Velha" (1889-1930). Este período ficou marcado pelo domínio político e econômico exclusivo de oligarquias dominantes nos estados, impossibilitando a participação democrática de amplos setores da sociedade. Em tal contexto, verificam-se lógicas regionalistas e privatistas no jogo político, o predomínio do familismo, das fraudes eleitorais e das restrições do direito ao voto para a maioria da população brasileira. No presente trabalho, nos deteremos na análise da seção do estado do Paraná, fundada em janeiro de 1927. Tal organização fazia parte de um plantel de movimentos sociais antioligárquicos que se intensificaram nos anos 1920, caracterizados pela incrementação da urbanização e da industrialização, que traziam as inquietações se segmentos sociais como os operários, os comerciários, os profissionais liberais, entre outros. Estes agrupamentos sociais se organizaram em sindicatos, partidos e outras organizações de protesto social para lutar contra o sistema político e social oligárquico. O protesto militar do Tenentismo contra as oligarquias também possuiu atuação significativa. Nesse contexto, o Partido Democrático surgiu como uma dissidência dos grupos estaduais oligárquicos hegemônicos, que se auto intitulava como uma organização que defendia os interesses de amplos setores sociais, clamando em prol dos anseios da indústria, do comércio, da classe média e da classe trabalhadora. Para a discussão crítica que indaga as possíveis rupturas que tal organização preconizava para as práticas políticas locais, temos como referência os estudos de Ricardo Costa de Oliveira no que se refere à questão da reprodução do poder das famílias na política paranaense ao longo dos séculos e de Pierre Bourdieu a respeito dos "capitais" nos quais os agentes são portadores que determinam sua posição no "campo" político. Concentraremos nossas atenções na análise dos atributos e heranças sociais destes agentes, estabelecendo relações com suas práticas no "jogo político" no qual os mesmos estavam inseridos. Assim, confrontaremos os ideais do partido com as suas práticas reais, averiguando quais eram as famílias que seus dirigentes pertenciam e que interesses representavam, identificando as classes e frações de classe de pertencimento dos mesmos. Também nos debruçaremos sobre a atuação destes dirigentes e seus grupos familiares na Revolução de 1930, verificando se tal acontecimento político potencializou os capitais destas oligarquias não-hegemônicas que estavam insatisfeitas com o jogo político característico da República Velha. Para tal análise, verificaremos as ocorrências dos nomes e dos troncos familiares em que os dirigentes pertenciam na obra "Genealogia Paranaense", de Francisco Negrão. Também coletaremos variáveis biográficas como nome, filiação, local de nascimento, cargos políticos ocupados, profissão e partido político de origem dos agentes que faziam parte da direção do Partido Democrático Paranaense.
\end{abstract}

Palavras-Chave: Política Paranaense. Família. Partido Democrático.

\section{The Parana Democratic Party from 1927 to 1930: a study of the family and social capitals of its}

\begin{abstract}
This paper aims to map a genealogical and social profile of the leaders of the Democratic Party in Paraná. This association appeared in the state of São Paulo and later spread to other states of the federation in the context of the First Republic or "Old Republic" (1889-1930). This period was marked by the exclusive political and economic domination of dominant oligarchies in the states, precluding the democratic participation of others sectors of society. In this context, there are regionalist and privatist logics in the political game, the prevalence of familism, electoral fraud and the restrictions of the right to vote for the majority of the Brazilian population. In the present work, we will focus on the analysis of the section of the state of Paraná, founded in January 1927. This organization was part of a group of anti-oligarchic social movements that intensified in the 1920s, characterized

\footnotetext{
${ }^{1}$ Doutoranda em Sociologia pela Universidade Federal do Paraná. Mestre em Sociologia e Graduada em Ciências Sociais (Licenciatura e Bacharelado) pela Universidade Federal do Paraná. Integrante do Núcleo de Estudos Paranaenses (NEP-UFPR). Bolsista da CAPES. E-mail para contato: nataliagranato@ hotmail.com.
} 
by the increase of urbanization and industrialization, which brought the concerns of social segments such as the workers, the traders, the professionals, among others. These social groupings have organized themselves into unions, parties and other social protest organizations to fight against the oligarchic political and social system. The military protest of Tenentismo against the oligarchies also had significant action. In this context, the Democratic Party emerged as a dissent from the hegemonic oligarchic state groups, which it called itself an organization that defended the interests of a larger number social sectors, calling for the yearnings of industry, commerce, the middle class and the working class. For the critical discussion that questions the possible ruptures that such an organization advocated for local political practices, we have as reference the studies of Ricardo Costa de Oliveira regarding the issue of the reproduction of the power of families in the politics of Paraná over the centuries and Pierre Bourdieu on "capitals" in which agents are carriers that determine their position in the political "field". We will focus our attention on the analysis of the attributes and social inheritance of these agents, establishing relations with their practices in the "political game" in which they were inserted. Thus, we will confront the ideals of the party with their actual practices, ascertaining which families their leaders belonged and which interests they represented, identifying the class and class fractions of their belonging. We will also look at the performance of these leaders and their family groups in the 1930 Revolution, verifying whether such a political event has potentiated the capitals of these non-hegemonic oligarchies that were dissatisfied with the political game characteristic of the Old Republic. For this analysis, we will verify the occurrences of the family names and trunks in which the leaders belonged in the work "Genealogia Paranaense", by Francisco Negrão. We will also collect biographical variables such as name, filiation, place of birth, occupied political positions, profession and political party of origin of the agents that were part of the direction of the Parana Democratic Party.

Key words: Politics of Paraná. Family. Democratic Party.

*Enviado em 30/05/2018.

*Aceito em 19/06/2018.

\section{Introdução}

O presente trabalho pretende investigar o perfil genealógico e social da primeira diretoria do Partido Democrático no Paraná. Esta legenda surgiu no estado de São Paulo e se espalhou por outros estados da federação no contexto da Primeira República ou "República Velha” (1889-1930), período que ficou marcado pelo domínio político e econômico exclusivo de oligarquias dominantes nos estados, impossibilitando a participação democrática de amplos setores da sociedade, como os operários, os comerciantes, os profissionais liberais e a classe média e frações de classe economicamente dominante que não se sentiam contemplados pelas políticas governamentais hegemônicas. Em tal contexto, verificam-se lógicas regionalistas e privatistas no jogo político, o predomínio do familismo, das fraudes eleitorais e das restrições do direito ao voto para a maioria da população brasileira. Como uma reação a tais lógicas, uma série de organizações e movimentos sociais antioligárquicos e dissidências oligárquicas se fortaleceram a partir da década de 1920, em um cenário de crescentes inquietações e transformações incrementadas pela urbanização e pela industrialização.

Temos como objeto, entre estas organizações de protesto oligárquico, o Partido Democrático Paranaense, fundado em janeiro de 1927, como uma dissidência dos grupos 
estaduais oligárquicos hegemônicos, que se auto intitulava como uma organização que defendia os interesses de amplos setores sociais, clamando em prol dos anseios da indústria, do comércio, da classe média e da classe trabalhadora.

Este trabalho está dividido em quatro partes. A primeira discorre sobre uma parte da produção acadêmica que tem como objeto específico o Partido Democrático e suas origens no estado de São Paulo.

A segunda parte propõe uma discussão teórico-metodológica que possibilita a análise da diretoria do Partido Democrático Paranaense. Após estas considerações, a terceira etapa do trabalho levantará informações biográficas fundamentais dos agentes que faziam parte da direção do Partido Democrático Paranaense, com o objetivo de assinalar quais são os principais “capitais" e a atuação política dos mesmos.

Por sua vez, a quarta parte assinalará os interesses que esta agremiação representava, suas relações com a classe dominante local e as formas de atuação política de alguns destes agentes no período pós-Revolução de 1930.

\section{Algumas abordagens sobre o Partido Democrático na produção historiográfica}

O Partido Democrático foi uma organização política que começou suas atividades durante a década de 1920, com a fundação da seção paulista, em fevereiro de 1926. Uma de suas principais premissas era a de "republicanizar a república", ou seja, resgatar os valores democráticos, morais e políticos esquecidos ou fragilizados pelas práticas ao longo das décadas, principalmente devido à hegemonia política exercida pelo Partido Republicano Paulista, contestada pelos membros da agremiação. O discurso ideológico de democracia versus oligarquia era o mote da contraposição entre o Partido Democrático e o Partido Republicano, recorrente em muitos manifestos e declarações (PRADO, 1986).

Uma das interpretações mais influentes na historiografia sobre o Partido Democrático é a de Boris Fausto. O autor analisa esta agremiação com a intenção de articular seu perfil com as ações dissidentes que culminaram na Revolução de 1930, movimento que supostamente estaria relacionado aos interesses modernizadores da indústria, em contraposição aos setores tradicionais que afirmavam os interesses de grupos mais específicos, como os agroexportadores. Para Fausto (1986, p.38), o PD de São Paulo representava a aliança das classes médias tradicionais com oligarquias dissidentes do setor agrário, não se associando com a modernização industrial a partir do momento em que se afirmava portador de uma visão 
agrarista da sociedade brasileira. A associação entre o PD de São Paulo, as classes médias e setores dissidentes da economia cafeeira é demonstrada com a constatação de que seus principais integrantes eram profissionais liberais e filhos de fazendeiros de café descontentes com a hegemonia do Partido Republicano Paulista. Uma das fontes citadas que corroboram com esta argumentação refere-se às 599 assinaturas de lançamento do Partido Democrático, das quais $89 \%$ referiam-se a profissionais liberais, em contraposição ao pequeno número de 11 industriais que assinaram a fundação do partido (FAUSTO, 2004, p.444).

Contrapondo-se a tal interpretação, Maria Lígia Coelho Prado (1986, p.17) assinala as limitações de correlacionar apenas a variável profissão com a classe social dos assinantes da fundação do Partido Democrático. Este método utilizado por Fausto associou os profissionais liberais com as classes médias. Em uma pesquisa biográfica que focalizava os dirigentes da agremiação, Prado levantou outras variáveis, como atividades econômicas e laços de parentesco dos membros do $\mathrm{PD}$, assinalando que os mesmos pertenciam não às classes médias, mas às classes proprietárias (PRADO, 1986, p.18). Diante de tais dados, a autora destaca que a oposição entre o Partido Democrático de São Paulo e o Partido Republicano Paulista era mais retórica do que concreta, visto que ambos representavam os interesses das principais frações da classe economicamente dominante.

Estes dois autores citados analisam o Partido Democrático de São Paulo. No Paraná, não há um trabalho específico que trate desta agremiação. A organização foi mencionada na tese de Mônica Goulart (2008) sobre a Assembleia Legislativa do Paraná, juntamente com o seu manifesto de lançamento. Também há outras menções esparsas, em livros de memórias os volumes escritos por Luiz Carlos Pereira Tourinho (1990) ou de estudos histórico-jornalísticos como a obra de Samuel Guimarães da Costa (1995).

Em linhas gerais, o discurso político do Partido Democrático Paranaense está evidenciado no seu manifesto de lançamento eleitoral, datado de janeiro de 1927. O documento projeta a candidatura de David Carneiro a deputado federal nas eleições daquele ano como um elemento de união das discordâncias do "povo", da indústria e do comércio em relação às práticas adotadas pelo Partido Republicano que evidenciavam a "decadência dos costumes políticos" e o "falseamento da democracia" (MANIFESTO, 25. Jan. 1927, p.3). Trata-se de uma nova agremiação que concilia os interesses das "classes conservadoras" (ou seja, as classes proprietárias, em especial as associadas à indústria e o comércio) com os interesses da "classe operária”, classes não contempladas adequadamente pelo jogo político da situação hegemonizada pelo Partido Republicano. A renovação democrática teria a liderança da 
Associação Comercial do Paraná, reunida no interior do Partido Democrático, que moralizaria os costumes políticos através de um sentimento de patriotismo e coletivismo, e conciliaria as forças do capital e do trabalho por um novo pacto de solidariedade. A tarefa de "democratizar a República" seria realizada pelo esforço comum do "povo". No caso do Paraná, este anseio tinha a diretoria do Partido Democrático como seu aliado, contando com os seguintes membros que assinaram a carta: João Guilherme Guimarães, Antônio Augusto Carvalho Chaves, Benjamin Lins, Francisco Xavier Teixeira de Carvalho, Antônio Jorge Machado Lima, Ângelo Guarinello e Fidélis Reginato (MANIFESTO, 25. Jan. 1927, p.3).

O presente trabalho buscará informações biográficas e genealógicas que traçarão um perfil destes dirigentes, cuja análise seguirá as indicações teórico-metodológicas tratadas na próxima seção. Outros dirigentes partidários que não estão presentes nesta lista, como Benjamin Pessoa, Manoel de Alencar Guimarães, Joaquim Pereira de Macedo e Ulysses Falcão Vieira também serão contemplados, totalizando 12 dirigentes, contando com David Carneiro.

\section{O Partido Democrático Paranaense: indicações teórico-metodológicas para a sua análise}

Conforme o visto, o Partido Democrático se opunha as práticas oligárquicas dominantes nos estados, hegemonizados pelo Partido Republicano. Estas organizações se enquadram como dissidências oligárquicas que, cujas práticas conjuntas com outros movimentos sociais e políticos, culminaram na Revolução de 1930. Para a discussão crítica que indaga as possíveis rupturas que tal organização preconizava para as práticas políticas locais, temos como referência as indicações de Ricardo Costa de Oliveira referentes às questões sobre a reprodução do poder das famílias na política paranaense ao longo dos séculos e de Pierre Bourdieu a respeito dos "capitais" nos quais os agentes são portadores que determinam sua posição no “campo" político.

Uma das principais fontes para a análise da classe dominante no Paraná é a obra “Genealogia Paranaense”, de Francisco Negrão. A tese de Ricardo Costa de Oliveira (2000) articula a análise genealógica de Negrão com a formação e o desenvolvimento da classe dominante local, identificando aproximadamente 45 famílias históricas do período colonial perpetuam a dominação econômica, política e cultural ao longo dos séculos, em detrimento das transformações políticas e modernização no capitalismo. A Genealogia Paranaense é o catálogo do percurso familiar dos primeiros povoadores do Paraná, no século XVII, até a data de 
publicação da obra, na década de 1920 , do volume I ao volume VI, que indica uma classe dominante composta por um "reduzido conjunto de famílias, bastante aparentadas entre si e compartilhando inúmeros ascendentes em comum" (OLIVEIRA, 2000, p.5). Cada um dos volumes evidencia os títulos genealógicos ${ }^{2}$ de pertencimento dos indivíduos citados, indicando a rede de parentesco dos seus portadores (OLIVEIRA, 2000, p. 214).

A partir desta linha de discussão teórico-analítica, verificaremos o pertencimento dos membros do Partido Democrático Paranaense no interior da classe dominante tradicional, que perpetua historicamente sua dominação política, econômica e social. Destacamos as limitações da abordagem feita por Boris Fausto, que identifica o Partido Democrático de São Paulo como uma agremiação de classe média com características antiindustrialistas apenas com a informação da profissão de seus membros. Tal interpretação é recorrente nas menções ao Partido Democrático, agremiação que carece de estudos aprofundados, principalmente nas suas manifestações nos estados, levando em consideração suas características locais e peculiares, que não são meros reflexos do modelo paulista.

Nossa linha de análise leva em consideração o Partido Democrático Paranaense e suas características locais. No entanto, não destacaremos tal agremiação como fechada em si mesma, sem conexão com outras seções estaduais, em especial na mais importante delas, a seção paulista. Algumas indicações de Maria Lígia Coelho Prado (1986) para o estudo do Partido Democrático de São Paulo são proveitosas para o presente trabalho, especialmente quando a autora assinala a necessidade da análise de dados biográficos e as ligações de parentesco dos membros do PD paulista em relação aos membros do Partido Republicano de São Paulo. Nossa análise destaca as informações biográficas e vai além destas, empreendendo uma abordagem genealógica para o estudo do Partido Democrático Paranaense, com o objetivo de articular o pertencimento dos seus membros à classe dominante nas esferas políticas, econômicas e sociais.

O embasamento teórico sobre a noção de classe dominante tem como principal referência a obra de Pierre Bourdieu, que entende a sociedade ou o macrocosmo social como um espaço dividido e inter-relacionado em campos sociais. Tendo em vista que os agentes

\footnotetext{
2 O volume I corresponde aos descendentes de Baltazar Carrasco dos Reis, o volume II corresponde aos descendentes de João Rodrigues Seixas, o volume III corresponde aos descendentes de João Rodrigues de França. A partir do volume IV, são variados títulos genealógicos, a saber: Volume IV: Títulos Laras, Moraes Cordeiro, Mateus Leme, Teixeira de Azevedo, Xavier Pinto, Teixeira Coelho, Pereira Braga e Oliveira Cardoso. Volume V: Títulos Corrêa de Bittencourt, Cardoso de Lima, Taques, Oliveira Vianna, Goés Siqueira, Alves, Marques da Cunha e Azevedo da Silveira. Volume VI: Títulos Macedo, Laynes, Morocine Borba, Martins Lopes, Brandão de Proença, Simas, Souza Pinto, Rodrigues Vianna, Gonçalves Marques, Marques de Jesus, Silva Pereira, Santos, Nascimento de Farias, Maravalhas, Pereiras, Mendonça, Pereira Branco, Freitas de Saldanha, Alvares de Araújo, Soares da Costa, Xavier da Silva, Falcão Bastos, Moreira da Rocha, Gonçalves dos Santos, Pletz, Muller, Kalckman e Bley. (OLIVEIRA, 2000, pp.380-385; NEGRÃO, 2004).
} 
analisados estão inseridos em diferentes campos/sub-campos da vida social, consideraremos como espaços centrais de reconhecimento simbólico os seguintes campos: o político, o social/econômico e o cultural/intelectual. Cada campo é um microcosmo, uma parcela do mundo social (ou macrocosmo) relativamente autônomo em relação à totalidade do mundo social (BOURDIEU, 2011, p.195). Relativa autonomia, pois "os campos não são espaços com fronteiras estritamente delimitadas, totalmente autônomos" (BONNEWITZ, 2003, p.62). Assim, os campos podem se entrecruzar-se, e a inserção de cada agente analisado em diferentes campos proporciona a acumulação de capitais que são decisivos para a noção da posição que tal agente vai ocupar no mundo social. Os "campos", que permeiam a vida social, são compostos de agentes com capitais desiguais que reproduzem o sistema de dominação. Verificaremos o volume dos capitais dos quais os agentes em análise são portadores para assinalar o pertencimento destes na classe dominante paranaense, ainda que os mesmos não se identificassem com as oligarquias hegemônicas no estado na conjuntura da década de 1920 .

Concentraremos nossas atenções na análise dos atributos e heranças sociais destes agentes, estabelecendo relações com suas práticas no "jogo político" no qual os mesmos estavam inseridos. Assim, confrontaremos os ideais do partido com as suas práticas reais, averiguando quais eram as famílias que seus dirigentes pertenciam e que interesses representavam, identificando as classes e frações de classe de pertencimento dos mesmos. Também nos debruçaremos sobre a atuação destes dirigentes e seus grupos familiares na Revolução de 1930, verificando se tal acontecimento político potencializou os capitais destas oligarquias não-hegemônicas que estavam insatisfeitas com o jogo político característico da República Velha.

\section{Levantamento biográfico e genealógico dos dirigentes}

Esta seção objetiva apresentar um levantamento biográfico e genealógico da primeira diretoria do Partido Democrático Paranaense, pretendendo traçar um perfil geral dos membros dominantes de tal agremiação. Os primeiros perfis biográficos e genealógicos dos dirigentes serão dos paranaenses que compunham a agremiação. Por sua vez, os perfis dos dirigentes não nascidos no Paraná serão contemplados. 
O primeiro presidente do PD Paranaense, o comendador João Guilherme Guimarães, nasceu na cidade de Paranaguá, em 1857, filho do Visconde de Nácar ${ }^{3}$ (Manoel Antônio Guimarães) e de Rosa Correia Guimarães. É portador do título genealógico Rodrigues de França. Casou-se com Clotilde Miró Guimarães (NEGRÃO, 2004, vol IV, p.366), filha de Manoel Miró, comerciante e industrial da erva-mate em Antonina. Sua associação com a classe dominante tradicional paranaense é evidente.

O clã Guimarães faz parte do plantel de famílias históricas da classe dominante paranaense (OLIVEIRA, 2000, p.389). Sua atuação local data de meados do século XVIII, no contexto em que o coronel português Manoel Gonçalves Guimarães se estabeleceu como grande proprietário de terras, tropeiro, contratador de impostos de Porto de Cima e Rio Negro e minerador em Tibagi (OLIVEIRA, 2000, p.389).

João Guilherme Guimarães é um dos herdeiros dos capitais econômicos acumulados pela sua família. Porém, sua influência política era reduzida comparada à geração familiar anterior. Os únicos cargos que o mesmo exerceu foi como vereador e prefeito de Paranaguá. Na ocasião em que ocupou este indispôs-se com o chefe político local, Vicente Machado, na qual o mesmo solicitou a remessa de uma boa quantidade de dinheiro de Paranaguá para os cofres do Estado. Negando tal pedido, abandonou a prefeitura (CARNEIRO, 1981, p.100). Após este episódio, abandonou a política por um tempo, retomando suas atividades na década de 1920, de uma maneira contra hegemônica em relação aos círculos dominantes. Esta característica de dissidência também está presente na trajetória do seu sobrinho, Manoel de Alencar Guimarães, nascido em 1865 (atuando na mesma geração de João Guilherme Guimarães). Este agente desempenhou os cargos de juiz municipal, chefe de polícia, secretário de estatística, deputado estadual em 1892, deputado federal em 1894, reelegendo-se em 1900. Exerceu interinamente a presidência do estado em 1908. Senador por cinco legislaturas, liderou a dissidência no Partido Republicano Paranaense, denominada "Coligação Republicana",

\footnotetext{
${ }^{3}$ Seu pai foi vice-presidente do estado, assumindo interinamente a presidência em 1873 e 1877 . Com uma atividade política e econômica intensa, Manoel Antônio Guimarães foi um dos maiores ervateiros e grande proprietário rural escravista (OLIVEIRA, 2007, p.161). Suas atividades políticas começaram a nível local, como vereador e presidente da Câmara Municipal de Paranaguá, cidade onde também foi delegado de polícia, juiz municipal e comandante da Guarda Nacional. Em nível estadual, foi deputado na Assembleia Provincial de São Paulo, antes da emancipação do Paraná, e Deputado Provincial no Paraná, cargo no qual ocupou a presidência da Assembleia. Foi vice-presidente do Paraná por várias ocasiões, além de ter exercido o cargo de presidente do Paraná entre 1873 e 1877. Também ocupou o cargo de deputado geral, entre 1886 e 1889 (CARNEIRO, 1962, p.99). No seu primeiro casamento, contraiu núpcia com uma das filhas de Manoel Francisco Correia (o Velho), Maria Clara Correia. Viúvo, contraiu segunda núpcia com sua cunhada, Rosa Narcisa Correia, mãe de João Guilherme Guimarães. A influência política de Manoel Antônio Guimarães teve como auge a ocasião em que hospedou o imperador Dom Pedro II e comitiva na sua residência em Paranaguá, em 1880. Naquele mesmo ano, foi nomeado Visconde pelo imperador. Fundou a firma Guimarães e Cia, uma das mais antigas do Paraná e do Brasil à dedicação ao comércio de erva-mate. (COSTA, 1995, p.64).
} 
rompendo com o então presidente do estado Carlos Cavalcanti e criticando Affonso Camargo 4 . Com tais rompimentos, viu sua carreira política no Paraná declinar, mudando-se para o Rio de Janeiro, onde, em 1922, exerceu o cargo de tesoureiro na Comissão do Centenário da Independência, a convite do presidente Epitácio Pessoa. No ano de 1927, durante o governo Washington Luiz, foi nomeado Inspetor Consular para a América do Sul e Sul da África (CASA CIVIL $\left.^{5}\right)$.

Estas trajetórias indicam que alguns importantes membros da família Guimarães participavam de dissidências em relação ao situacionismo e se engajaram no Partido Democrático, abrindo possibilidades de incrementação de capitais políticos após a Revolução de 1930. No caso da família Guimarães, constatamos a insatisfação política de membros da classe dominante tradicional, que exerciam protagonismo na economia local, dada a vinculação entre o Partido Democrático e a Associação Comercial do Paraná (ACP). Este partido possuía como endereço o Palácio do Comércio, sede da ACP, e foi organizado no interior desta entidade através da realização de conferências entre industriais e comerciantes que sentiam a necessidade da organização política coletiva, por meio de uma agremiação política e da fundação de jornais independentes. (MANIFESTO, 28.jan.1927, p.2). João Guilherme Guimarães foi um dos defensores da atuação dos empresários e comerciantes na política (CARNEIRO, 1981, p.100), ou as chamadas "classes produtoras" do país (os agricultores, pecuaristas, industriais e comerciantes), e atuou intensivamente em prol da representação política do empresariado no Partido Democrático e na Associação Comercial do Paraná. Também fundou os jornais políticos "A Ordem", "O Constituinte", e "A Nação" e também era um dos maiores acionistas da Gazeta do Povo $^{6}$, jornal de oposição aos círculos dominantes oligárquicos, fundado em 1919.

Gerações da família Guimarães perpetuaram ${ }^{7}$ suas influências políticas e econômicas. Os filhos de João Guilherme Guimarães, Arcésio e Acrisio Guimarães exerceram a chefia da firma Guimarães e cia. Arcécio Guimarães inclusive foi um dos presidentes da Associação Comercial do Paraná na década de 1930. Outros destacados membros da família que fazemos

\footnotetext{
${ }^{4}$ Manoel de Alencar Guimarães. Disponível em: http://www.casacivil.pr.gov.br/modules/conteudo/conteudo.php?conteudo=45. Acesso em: 12 abr.2018.

${ }^{5}$ CASA CIVIL. Disponível em: http://www.casacivil.pr.gov.br/modules/conteudo/conteudo.php?conteudo=45. Acesso em 18. Abr.2018.

${ }^{6}$ JOÃO Guilherme Guimarães http://msinstituto.blogspot.com.br/2016/07/joao-guilherme-guimaraes.html

${ }^{7}$ No seguinte trecho de um artido sobre as famílias dominantes no Paraná no ano de 2007, Ricardo Costa de Oliveira menciona os seguintes descendentes de Manoel Antônio Guimarães: "Patriarcas e oligarcas têm outros descendentes na atual legislatura. Fernando Ribas Carli Filho é filho do prefeito de Guarapuava, Fernando Ribas Carli, e bisneto do falecido senador Flávio Guimarães. Plauto Miró Guimarães, tio de Fernando Ribas Carli Filho, é também neto do Senador Flávio Guimarães, todos descendentes de Manoel Antonio Guimarães, o Visconde de Nácar" (OLIVEIRA, 2007, p.162)
} 
menção e exerceram notáveis cargos políticos após a Revolução de 1930 e perpetuaram seus capitais ao longo do século XX referem-se a Flávio Guimarães, Algacyr Guimarães, Alô Ticoulat Guimarães, Acyr Guimarães, Noel Lobo Guimarães, etc ${ }^{8}$.

Por sua vez, Joaquim Pereira de Macedo nasceu em Porto de Cima, 1858, filho do comerciante Manoel Ribeiro de Macedo e Francisca Pereira de Macedo. As conexões com a classe dominante tradicional são evidentes na sua genealogia. Tendo como referência a obra de Negrão (2004), verificamos que o agente é portador do Título Rodrigues Seixas (Vol.II), por nascimento, pertencendo à família Macedo. Um dos filhos do casal, Manoel Pereira de Macedo, casou-se com Hilda de Macedo Cortes, outra ramificação importante da família Macedo. Outro Título do qual é portador é o Rodrigues de França (Vol.III), pois uma das filhas do casal, Alcina Macedo, contraiu matrimônio com Acyr Guimarães, redator-chefe da Gazeta do Povo. Por sua vez, também é portador do Título Pletz (Vol.VI), pelo casamento com Adelaide de Azevedo Müller de Macedo, filha do Coronel José Mathias Müller

Joaquim Macedo era industrial da erva-mate e do trigo, proprietário do único moinho existente até então. Sua atuação política começou no litoral, exercendo a superintendência do ensino de Porto de Cima. Tinha notoriedade no Império, sendo nomeado pela Princesa Isabel para o cargo de coronel comandante superior da Guarda Nacional no município de Palmeira Nesta cidade, também ocupou a delegacia de polícia, a prefeitura e a vice-prefeitura (NICOLAS, 1984). Foi deputado constituinte, deputado estadual na primeira legislatura republicana, em 1892, e presidente da Assembleia Legislativa, em 1900 (GOULART, 2008, p. 249 e 518). Em Curitiba, foi vereador e Prefeito por duas legislaturas: de 1908 a 1911 e de 1930 a 1932. Observa-se na trajetória de Joaquim Macedo uma atividade política intensa nos primeiros anos da República, um declínio entre as décadas de 1910 e 1920 e uma recolocação nos círculos dominantes a partir da Revolução de 1930. Sua participação na diretoria do Partido Democrático Paranaense enquanto um oligarca dissidente foi decisiva para esta incrementação de capitais de notoriedade.

O principal líder do Partido Democrático Paranaense, David Carneiro, nasceu em 25 de julho de 1879, na cidade de Antonina, filho do ervateiro e industrial David Antônio da Silva Carneiro e de Maria Olympia da Costa Carneiro. É portador de muitos títulos genealógicos da obra de Negrão (2004, Volume I, p.197, 221; II, p.92; Vol.III, p.552; Vol.VI, p.333). Do Título Carrasco dos Reis, através dos laços de casamento com Alice Monteiro Carneiro. Uma de suas

\footnotetext{
${ }^{8}$ Para informações mais detalhadas dos membros influentes da família Guimarães, ver o artigo de Granato (2017) Os senadores do Paraná no contexto da Revolução de 1930: capitais políticos e familiares, que menciona importantes conexões familiares do senador Flávio Guimarães.
} 
irmãs, Josephina Costa Carneiro, foi casada com o Tenente Coronel José Cândido da Silva Muricy, engenheiro militar, deputado estadual de 1895 a 1905, sócio fundador do Instituto Histórico e Geográfico do Paraná. Outra irmã, Maria Augusta Carneiro de Loyola, casou-se com José Guilherme de Loyola, médico e diretor do serviço de higiene e hospitais, deputado eleito nos anos de 1902 e 1906 e professor da Universidade do Paraná. Também é portador do Título Rodrigues de França, pois um dos seus filhos, David Carneiro Júnior, casou-se com Marília Suplicy de Lacerda. Porta o Título Soares da Costa (Vol.VI), por ser filho de Maria Olympia da Costa Carneiro

A descendência direta dos Carneiro no Paraná remete-se ao patriarca David Carneiro, nascido em Iguape, São Paulo, seu primeiro cargo político foi o de Coletor de Rendas de Antonina, substituindo o seu parente, o padre José Alves Carneiro, da investidura do cargo. Carneiro conseguiu o cargo devido à sua condição de secretário particular de Zacarias de Góes e Vasconcelos, o primeiro presidente da província do Paraná (MACHADO, 2012, p.21). Desde então, inseriu-se nos negócios da erva-mate, sendo funcionário e posteriormente sócio de Ildefonso Pereira Correia, o Barão do Serro Azul ${ }^{9}$. Estabeleceu-se com a empresa David Carneiro e Cia, a partir de 1894 (OLIVEIRA, 2000, p.277).

Seu pai foi presidente da Associação Comercial do Paraná em 1898. Quando assumiu os negócios familiares que envolviam a indústria do mate, foi inovador na forma em que se relacionava com os seus empregados em termos de questões trabalhistas e assistência social. Segundo o seu parente Newton Carneiro (1965), foi um "Precursor da Justiça Social” no Brasil.

David Carneiro não tinha influência política, mas exercia notável influência econômica na indústria da erva-mate, incrementada com o cargo de presidente da Associação Comercial do Paraná. Era um dos principais líderes das dissidências oligárquicas do Paraná, sendo escolhido o candidato do Partido Democrático a deputado federal. Poderia ter exercido a liderança civil da Revolução de 1930, se não tivesse falecido, em 1928. Seu filho foi um dos mais importantes historiadores do Paraná nas décadas posteriores.

Outro membro da classe dominante tradicional e dirigente do Partido Democrático é Antônio Jorge Machado Lima. Portador dos títulos genealógicos Carrasco dos Reis e

\footnotetext{
${ }^{9}$ A família Carneiro nutriu rancores com o fuzilamento do Barão do Serro Azul pelas tropas legalistas na ocasião da Revolução Federalista. As gerações posteriores foram críticas em relação ao regime republicano. David Carneiro Júnior tinha uma perspectiva de oposição ao situacionismo e às oligarquias hegemônicas, contradição vivida no próprio casamento, uma vez que casou com Alice Bueno Monteiro, filha do Coronel Joaquim Monteiro de Carvalho e Silva, empresário e chefe político pertencente ao Partido Republicano e presidente da Junta Comercial do Paraná, membro da oligarquia dominante (MACHADO, 2012, p.25). Os capitais políticos do sogro de David Carneiro eram notáveis, exercendo diversos cargos, o mais importante deles, a presidência do Paraná, em 1890, 1907 e 1908, e também de membro da Junta Governativa do Paraná em 1892.
} 
Rodrigues de França, nasceu em Ponta Grossa, no ano de 1886, é um dos filhos do casal Vicente Machado da Silva Lima e Maria Antônia Machado Lima. Seu pai foi Deputado Provincial (de 1886 a 1889), Deputado Estadual (de 1891 a 1892, de 1896 a 1903) Senador pelo Paraná (18951902) e presidente do Paraná (1893-1894 e 1904-1907), um dos mais notáveis políticos do período pré-1930 (GOULART, 2008; OLIVEIRA, 2000; ALEP ${ }^{10}$; CASA CIVIL ${ }^{11}$ ). Membro de uma família estabelecida no Paraná desde meados do século XVIII, sendo descendente de Mateus Leme (CORRÊIA, 2004, p.244), um dos povoadores de Curitiba, Antônio Machado era casado com Zaira Abreu Machado, filha do senador Cândido Ferreira de Abreu. Seus familiares $^{12}$ tinham uma conexão imensa de conexões com a classe dominante tradicional paranaense.

Antônio Machado da Silva Lima formou-se pela Faculdade de Direito de São Paulo, no ano de 1907. Desempenhou o cargo de promotor público em Palmeiras e Antonina entre 1908 e 1909 e procurador fiscal e consultor jurídico da Fazenda Nacional na Delegacia Fiscal do Paraná, de 1909 a 1930. Fundou e dirigiu o jornal A Tarde, em 1928, opositor dos governos estadual e federal e amplo divulgador da Aliança Liberal no Paraná. Também detinha capitais culturais, sendo membro do Instituto Histórico e Geográfico do Paraná.

A rebeldia em relação às oligarquias dominantes do estado na trajetória de Antônio Machado é de longa data. Participou da dissidência liderada pelo senador Alencar Guimarães, exercendo oposição aos políticos dominantes, a partir do ano de 1914. Machado foi um dos líderes civis da Aliança Liberal, assumindo a secretaria geral e a presidência do diretório revolucionário no estado. No período pós-1930, ocupou a Diretoria geral do Ensino no Paraná, na interventoria do general Mário Tourinho (1930-1932) e integrou o Conselho Consultivo do estado, na interventoria de Manuel Ribas (1932-1935). Fundador do PSD, em 1933, eleito deputado federal constituinte no mesmo ano. Os deputados federais do Paraná que faziam parte

\footnotetext{
${ }^{10}$ ALEP. Disponívem em http://www.alep.pr.gov.br/deputados

${ }^{11}$ CASA CIVIL. Vicente Machado da Silva Lima. Disponível em: http://www.casacivil.pr.gov.br/modules/conteudo/conteudo.php?conteudo=36

${ }^{12}$ A irmã de Machado era casada com um filho de Carlos Cavalcanti (GOULART, 2008, p.128). Um irmão de Antônio Machado com grande influência na política é Caio Graccho Machado Lima, deputado estadual, de 1908 a 1909 e de 1930 a 1931. Foi um dos fundadores do PSD na década de 1930 (DAGOSTIM, 2011; GOULART, 2008). Fez parte do Conselheiro do Departamento Administrativo do Estado do Paraná de 1940 a 1941 , e de 1946 a 1947, sendo membro do Círculo de Estudos Bandeirantes e do Instituto Histórico e Geográfico do Paraná (DAGOSTIM, 2011, p.159). Um primo influente dos dois irmãos foi Ranulfo Pinheiro Lima, deputado federal em São Paulo, eleito no ano de 1935 (ALVES, 2003, p.229). Esta geração de irmãos e primos herdou capitais político das gerações anteriores, especialmente àquela inserida na política da República Velha. Um dos tios dos irmãos Antônio e Caio foi José Machado Pinheiro Lima, desembargador do Tribunal de Justiça de São Paulo (OLIVEIRA, 2000, p.391) e presidente desta mesma instituição em 1903, sendo este o pai do já citado Ranulfo Pinheiro Lima. Outro tio influente é Benigno Augusto Pinheiro Lima, coronel, deputado estadual de 1906 a 1907 e chefe político em Antonina (CORRÊIA, 2006, p.245; ALEP).
} 
da Assembleia Nacional Constituinte de 1934 escolheram o seu nome para ocupar o cargo de Senador a partir de 1935 (DICIONÁRIO CPDOC FGV ${ }^{13}$ ). Fundador do Partido Social Nacionalista do Paraná, foi apoiador da candidatura de José Américo de Almeida (candidato de Vargas) à presidência da República na eleição que se realizaria em 1938, impossibilitada pelo golpe do Estado Novo, ocorrido em 1937, que suspendeu mandatos, eleições e atividades legislativas (DICIONÁRIO CPDOC FGV). Durante o Estado Novo, ocupou os cargos de Procurador do Departamento de Finanças Públicas, em 1939 e Auditor do Tribunal de Contas da União, desde a década de 1940 (DICIONÁRIO CPDOC FGV).

Fidélis Manoel Reginato, outro dirigente do Partido Democrático Paranaense, era um conhecido cidadão casado com Antônia Peixoto Reginato, portadora do título Oliveira Cardoso (NEGRÃO, 2004, Vol. IV, p.364). Não há maiores informações biográficas sobre este agente, consta que o mesmo foi apoiador da Revolução de 1930.

A diretoria do Partido Democrático Paranaense também contava com Ulysses Falcão Vieira, nascido em Curitiba, no ano de 1885, filho de José Rodrigues Vieira e Cecília Falcão Vieira, portadora do título Corrêa de Bittencourt (NEGRÃO, 1926, V5, p.32-33). Formado em Direito, atuou como delegado de polícia em Curitiba e promotor público em Rio Negro, no ano de 1912 (BIOBIBLIOGRAFIA, 2011, p.54). Em 1914 foi eleito deputado na Assembleia Legislativa. (NICOLAS, 1984, p.326). No entanto, nas eleições de 1918, não obteve sucesso eleitoral. Voltou a ser deputado estadual somente na década de 1930, durante o governo provisório de Getúlio Vargas. Seus capitais sociais e acadêmicos eram de notoriedade, exercendo a presidência do Clube Curitibano, e do Centro de Letras do Paraná. Foi um dos fundadores e primeiro presidente da Academia Paranaense de Letras, entre os anos de 1936 e 1937, de 1936 a 1942 (BIOBIBLIOGRAFIA, 2011). Também foi diretor- proprietário do Diário da Tarde, professor de Direito da Universidade do Paraná e um dos redatores da Constituição Estadual de 1934 (BIOBIBLIOGRAFIA, 2011, p.54). Ulysses Vieira transmitiu capitais de notoriedade ao seu filho, José Rodrigues Vieira Netto, advogado, professor de Direito na Universidade do Paraná e eleito, em 1947, deputado estadual pelo Partido Comunista (HELM, 2013).

O único membro da diretoria do Partido Democrático Paranaense que não é mencionado pela Genealogia Paranaense é o Coronel Francisco Xaxier Teixeira de Carvalho. Advogado, fez parte do conselho pró-Vargas e foi membro da Aliança Liberal. Com a Revolução de 1930,

13 DICIONÀRIO CPDOC FGV. Verbete Antônio Jorge Machado Lima. Disponível em: http://www.fgv.br/cpdoc/acervo/dicionarios/verbete-biografico/lima-antonio-jorge-machado. 
foi nomeado membro da força militar do estado (O Dia, 11.11.30, p.5) e fiscal das agências dos bancos nacionais e estrangeiros estabelecidos em Curitiba ( $O$ dia, 24.10.30. capa). Suas atividades políticas foram interrompidas com o seu falecimento, no ano de 1931.

Outro agente político que foi um dos fundadores do Partido Democrático Paranaense foi Antônio Augusto de Carvalho Chaves. Tal agremiação congregava diversos membros nascidos fora do estado do Paraná. Chaves nasceu no ano de 1875, na cidade de Macaíba, no Rio Grande do Norte, filho de Joaquim Gonçalves Chaves Filho e Francisca de Carvalho Chaves. Seu pai foi um dos fundadores da Faculdade de Direito do Recife (BEVILAQUA, 1977). Em 1883, sua família transferiu-se para o Paraná Realizou o primário no Colégio Partenon Paranaense e o secundário e no colégio de propriedade do Professor Arthur Ferreira de Loyola, ambos localizados em Curitiba, formando boa parte da classe dominante paranaense do período (DICIONÁRIO CPDOC FGV).

Foi casado com Rosa de Carvalho Chaves. Seus descendentes contraíram contatos com a classe dominante local através de matrimônios que os integraram no círculo dominante local, com valorosos capitais jurídicos ${ }^{14}$. Uma das filhas do casal Chaves, Walkyria Chaves, casou-se com David Silveira da Motta, portador do título Rodrigues Seixas. Um importante membro do tronco Motta é Eusébio da Motta, desembargador, juiz e patrono de uma das cadeiras da Academia Paranaense de Letras (NEGRÃO VOL II, 2004, p.481; BIOBIBLIOGRAFIA, 2013).

Formou-se pela Faculdade de Direito de São Paulo, no ano de 1895 (DICIONÁRIO CPDOC FGV; CARNEIRO; VARGAS, 1994), seguindo os passos do seu pai, exercendo também o cargo de promotor público em Ribeirão Preto, no estado de São Paulo (DICIONÁRIO CPDOC FGV; CARNEIRO; VARGAS, 1994). Em 1896, retornou ao Paraná para exercer o cargo de secretário do Interior, Justiça e Instrução Pública, no governo de Francisco Xavier da Silva, cargo que exerceu até o ano de 1900, quando assumiu outra secretaria, a de Finanças, Comércio e Indústria, permanecendo até 1904, ano em que se elegeu deputado federal, sendo reeleito sucessivamente até 1914 (DICIONÁRIO CPDOC FGV; CARNEIRO; VARGAS,

\footnotetext{
${ }^{14}$ Transmitiu importantes capitais de notoriedade ao seu filho, Eduardo de Carvalho Chaves, que optou pela carreira militar, sendo nomeado por João Goulart a exercer a chefia do Estado-Maior do Exército em 1963 e do Departamento Geral de Pessoal do Exército entre 1963 e 1964, ocasião em que foi deposto pelo golpe e substituído pelo general Valdemar Levi Cardoso. Passou então para a reserva, sob a patente de Marechal, exercendo por muitos anos a docência no curso de Engenharia na Universidade Federal do Paraná (DICIONÁRIO CPDOC FGV). Verbete Antônio Augusto de Carvalho Chaves. Disponível em: http://www.fgv.br/cpdoc/acervo/dicionarios/verbete-biografico/antonio-augusto-de-carvalho-chaves. Acesso em 12 abr.2018.
} 
1994). Também acumulou o cargo de deputado estadual em alguns anos deste período, chegando a ser vice-presidente da Assembleia Legislativa em 1910 (GOULART, 2008, p. 520). Apoiador da Revolução de 1930, com a vitória do movimento foi nomeado presidente da Comissão de Sindicância do Paraná (DICIONÁRIO CPDOC FGV). Também exerceu a Secretário da Fazenda, Comércio e Indústria de 1930 a 1931, nos governos de Mário Tourinho e João Perneta. Eleito deputado estadual em 1934, entre os anos de 1935 e 1937 ocupou a presidência da Assembleia Legislativa (CARNEIRO; VARGAS, 1994), sendo um dos principais expoentes do Partido Social Democrático no Paraná. Durante a era Manoel Ribas, exerceu o cargo de governador interino entre junho e julho de 1935 e também foi membro do Conselho Administrativo (DASP) a partir de 1937 (CARNEIRO; VARGAS, 1994). Com a redemocratização, foi um dos principais organizadores do diretório do PSD no Paraná, exercendo a sua presidência. Também ocupou temporariamente a interventoria federal do Paraná, transmitindo-a para o recém-governador eleito, Moysés Lupion (DICIONÁRIO CPDOC FGV).

Outro membro da diretoria do Partido Democrático é Benjamin Pessoa, que nasceu na cidade de Bananeiras, na Paraíba, no ano de 1858, filho de Antônio Targino de Freitas Pessoa e Francisca da Cruz de Freitas Pessoa. Seu pai foi juiz de paz em Bananeiras (SOUZA, 1998). A família Targino e a família Pessoa são tradicionais no estado da Paraíba (MONTEIRO, 2016), acumulando capitais sociais, políticos, econômicos e jurídicos. Casou-se com Constancia de Faria Pessoa. Formado em 1879 pela Faculdade de Direito de Recife. Logo após sua formatura, iniciou sua carreira no Paraná, atuando como juiz nos municípios de Campo Largo e de Antonina. Também ocupou o cargo de auditor de guerra no $5^{\circ}$ Distrito Militar do Paraná (TJ PARANÁ ${ }^{15}$ ). A partir do ano de 1894, tornou-se desembargador do Tribunal de Justiça do Paraná. Exerceu o cargo de deputado na Assembleia Legislativa entre os anos de 1897 e 1914, no qual ocupou o cargo de $1^{\circ}$ vice-presidente da ALEP por 3 anos, de 1904 a 1907 (GOULART, 2008).

Outro dirigente fundador do Partido Democrático Paranaense foi Benjamin Baptista Lins D'Albuquerque, nascido na Paraíba, no ano de 1876. Filho do Capitão João Lins de Albuquerque Júnior e de Anna Carolina Baptista Lins de Albuquerque (AUTORIDADES ${ }^{16}$ ), pertencia a uma tradicional família paraibana, pelo tronco Albuquerque (MONTEIRO, 2016).

\footnotetext{
15 Des. Benjamin Américo de Freitas Pessoa. https://www.tjpr.jus.br/desembargadores-tjpr-museu//asset_publisher/V8xr/content/des-benjamin-americo-de-freitas-pessoa/397262?inheritRedirect=false

16 Disponível em: http://www.museumaconicoparanaense.com/MMPRaiz/Autoridades_PR/GOIndPR902_918Benjamin_Lins.htm
} 
Embora seus descendentes afirmem o pertencimento deste agente às classes mais baixas ${ }^{17}$, sua trajetória revela uma herança de capitais sociais e acadêmicos de relevância local. Segundo a página do Museu Maçônico Paranaense, Lins foi Grão Mestre do Grande Oriente e do Supremo Conselho do Paraná, entre os anos de 1914 a 1918 (AUTORIDADES ${ }^{18}$ ). Ainda segundo esta publicação, estudou na Faculdade de Direito do Recife. Após a formatura, em 1904, em 1907 se instalou em Curitiba, abrindo um escritório de advocacia em sociedade com Lindolpho Pessoa da Cruz Marques. Outras informações biográficas apontadas pela página do Museu Maçônico indicam que Benjamin Lins foi um dos responsáveis pela consolidação das leis municipais de Curitiba no ano de 1909, durante a gestão de Luiz Xavier a frente da Secretaria do Interior, Justiça e Instrução Pública. Neste período também começa a gestar a criação de uma Universidade no Paraná, fundada em 19 de dezembro de 1912. Benjamin Lins foi um dos primeiros professores de Direito na Universidade.

Em 1923 retomou suas atividades jornalísticas críticas ao situacionismo, sendo um dos fundadores do jornal "O Dia”, juntamente com David Carneiro. Em 1927, fez parte da primeira diretoria do Partido Democrático Paranaense. Segundo a página do Museu Maçônico Paranaense ${ }^{19}$, após a Revolução de 1930, ocupou a diretoria geral da Educação do Estado, no governo Mário Tourinho. Também no governo provisório de Vargas, ocupou o cargo de Procurador Regional da República, de 1933 a 1934.

Outro dirigente do Partido Democrático não paranaense é Ângelo Guarinello. Nascido em Pindamonhangaba, no ano de 1876, formou-se pela Faculdade de Direito de São Paulo e migrou para Curitiba, onde iniciou suas atividades profissionais. Desenvolvia intensas atividades literárias como poeta e fabulista, sendo integrante do Centro de Letras do Paraná a partir da década de 1920, exercendo diversas funções. É considerado um dos fundadores da Academia Paranaense de Letras, sendo o primeiro ocupante da cadeira ${ }^{\circ} 40$ desta instituição (BIOBIBLIOGRAFIA, 2011, p.276). Casou-se com Eleonora Gaissler, filha de Leocádia de

\footnotetext{
17 “A família de papai era muito pobre. Desde cedo ele teve de trabalhar para pagar o colégio e depois a faculdade. Naquele tempo, muitos "bacharéis do Norte" vinham para o Sul em busca de progresso e faziam sucesso porque eram cultos e inteligentes. Havia até o ditado: "São Paulo exporta café, o Norte exporta talentos." Meu pai foi severo, mas generoso" Entrevista com Enólia Lins de Loyola e Silva, filha de Benjamin Lins. Gazeta do Povo, 2.2.2009. Disponível em: http://www.gazetadopovo.com.br/especiais/90-anos/independencia/meu-pai-foi-severomas-generoso-beaoayfw1e3sjik08j1i5rc5q

18 Disponível em: http://www.museumaconicoparanaense.com/MMPRaiz/Autoridades_PR/GOIndPR902_918Benjamin_Lins.htm. Informações retiradas do livro: "A Maçonaria no Paraná” - Vol. 7 de 7, página 136 e 141 Registro de Direitos Autorais n ${ }^{\circ} 240.200$.

${ }^{19}$ Disponível em: http://www.museumaconicoparanaense.com/MMPRaiz/Autoridades_PR/GOIndPR902_918Benjamin_Lins.htm. Informações retiradas do livro: "A Maçonaria no Paraná” - Vol. 7 de 7, página 136 e 141 Registro de Direitos Autorais n ${ }^{\circ} 240.200$.
} 
Souza Gaissler e do coronel Paulo Emília Gaissler, capitalista de Curitiba, e portadora do título Oliveira Cardoso (NEGRÃO, 2004, Volume IV, p.566).

\section{Considerações Finais}

Neste trabalho, analisamos os perfis biográficos e genealógicos de 12 dirigentes do Partido Democrático Paranaense. Assinalamos a importância do estudo das especificidades locais das diversas seções do Partido Democrático, que não são reflexos da seção paulista. Neste estudo, constatamos resultados contrários às conclusões de Boris Fausto, em especial aquelas que referem-se ao Partido Democrático como uma agremiação de classe média e antiindustrialista. Através da análise empreendida, constatamos que 11 dos 12 dirigentes possuíam fortes vínculos com a classe dominante tradicional paranaense, através do nascimento ou dos matrimônios contraídos por estes dirigentes ou pelos seus filhos. Tais dirigentes acumularam diversas espécies de capitais econômicos e culturais antes de deterem mais recursos políticos, portencializados pela Revolução de 1930, movimento liderado pelas dissidências oligárquicas descontentes com o monopólio de uma minoria de agentes políticos dominantes do Partido Republicano, especialmente durante a década de 1920, durante os governos de Caetano Munhoz da Rocha e Affonso Camargo.

O Partido Democrático Paranaense também se apresenta como uma agremiação que não se opõe às forças industriais, visto que as atividades econômicas de seus dirigentes remetiamse, muitas vezes, à indústria ervateira, a atividade mais rentável e promissora do período, juntamente com a madeira. Esse argumento é fortalecido com o fato do Partido Democrático ter sua organização no interior da Associação Comercial do Paraná, organização identificada com a defesa dos interesses da indústria e do comércio, ou seja, frações de classe dominante descontentes com as políticas adotadas pelas oligarquias hegemônicas do Partido Republicano. Esta agremiação também busca contemplar algumas aspirações do movimento operário, apresentando um discurso reformista que evoca a necessidade de conciliação entre o capital e o trabalho.

Destacamos também que a maioria dos membros da diretoria do Partido Democrático e suas famílias exerciam atividades políticas de relevância entre o final do Império e o início da República e em um dado momento deste período (no primeiro momento, na Coligação Republicana e no segundo momento, entre o final da década de 1910 e a década de 1920), passaram a se identificar como dissidentes destas oligarquias, rompendo com as mesmas e 
participando de diversas organizações de oposição e protesto oligárquico, entre elas, o Partido Democrático.

\section{Bibliografia}

ALEP. Disponível em: http://www.alep.pr.gov.br/deputados. Acesso em 12 abr.2018.

ALVES, Luiz Antônio. A grande nação: Tibiriçá. São Paulo: EST edições, 2003.

AUTORIDADES.

Disponível

em:

http://www.museumaconicoparanaense.com/MMPRaiz/Autoridades_PR/GOIndPR902_918-

Benjamin_Lins.htm. Acesso em: 10 abr.2018

BEVILAQUA, Clóvis. História da Faculdade de Direito do Recife: edição comemorativa do sesquicentenário da instauração dos cursos jurídicos no Brasil, 1827-1977. Rio de Janeiro: Instituto Nacional do Livro, 1977.

BIOBIBLIOGRAFIA. Academia Paranaense de Letras: Organizado por Túlio Vargas, Valério Hoerner Júnior, Wilson Bóia. - ed. rev. por Albino Freire, Ernani Buchmann e Valério Hoerner Júnior. Curitiba: Academia Paranaense de Letras, 2011

BONNEWITZ, Patrice. Primeiras Lições sobre a sociologia de P. Bourdieu. Petrópolis: Vozes, 2003.

BOURDIEU, Pierre. "O campo político". In: Revista Brasileira de Ciência Política, n. 5, Brasília, jan-jul de 2011, pp.193-216.

CARNEIRO, David. Perfil histórico da Associação Comercial do Paraná e Galeria dos Presidentes. Curitiba: Reproset, 1981.

CARNEIRO, David; VARGAS, Túlio. História biográfica da república no Paraná. Curitiba: BANESTADO, 1994.

CARNEIRO, Newton. Um precursor da justiça social: David Carneiro e a economía Paranaense. Curitiba, 1965.

CASA CIVIL. Manoel de Alencar Guimarães. Disponível em: http://www.casacivil.pr.gov.br/modules/conteudo/conteudo.php?conteudo=45 . Acesso em 12 abr.2018.

CASA CIVIL. Vicente Machado da Silva Lima. Disponível em: http://www.casacivil.pr.gov.br/modules/conteudo/conteudo.php?conteudo=36 . Acesso em 12 abr.2018.

CORRÊIA, Amélia Siegel. Imprensa e Política no Paraná: uma prosopografia dos redatores republicanos. Clio- Revista de Pesquisa Histórica, n. 24, 2006

COSTA, Samuel Guimarães da. História Política da Assembleia Legislativa do Paraná (Volume I). Curitiba: Assembleia Legislativa do Paraná, 1995.

DAGOSTIM, Maristela Wessler. A república dos Conselhos: um estudo sobre a transformação do perfil da elite paranaense (1930-1947). Dissertação. Mestrado em Ciência Política. Curitiba: Universidade Federal do Paraná, 2011. 
DICIONÁRIO CPDOC FGV. Verbete Antônio Augusto de Carvalho Chaves. Disponível em: http://www.fgv.br/cpdoc/acervo/dicionarios/verbete-biografico/antonio-augusto-de-carvalhochaves. Acesso em 12 abr.2018.

DICIONÁRIO CPDOC FGV. Verbete Antônio Jorge Machado Lima. Disponível em: http://www.fgv.br/cpdoc/acervo/dicionarios/verbete-biografico/lima-antonio-jorge-machado Acesso em 12 abr.2018.

FAUSTO, Boris. A crise dos anos 20 e a Revolução de 1930. In: HOLANDA, Sérgio Buarque de; FAUSTO, Boris. (Orgs.). O Brasil republicano. (vol. 2). (Coleção: História Geral da Civilização Brasileira). Rio de Janeiro: Bertrand Brasil, 2004.

FAUSTO, Boris. A Revolução de 1930: Historiografia e História. São Paulo: Brasiliense, 1986.

GAZETA DO POVO. Disponível em: http://www.gazetadopovo.com.br/especiais/90anos/independencia/meu-pai-foi-severo-mas-generoso-beaoayfw 1e 3sjjk08j1i5rc5q Acesso em 10 abr. 2018.

GOULART, Mônica Helena Harrich Silva. Classe dominante e jogo político na Assembleia Legislativa paranaense (1889-1930). Tese. Doutorado em Sociologia. Curitiba: Universidade Federal do Paraná, 2008.

GRANATO, Natália Cristina. "Os senadores do Paraná no contexto da Revolução de 1930: capitais políticos e familiares". Revista NEP (Núcleo de Estudos Paranaenses), Curitiba, v.3, n.1, p. 46-63, maio 2017.

HELM, Cecília Maria Vieira. José Rodrigues Vieira Netto: A vida e o trabalho de um grande mestre. Curitiba: OAB Paraná, 2013.

JOÃO Guilherme Guimarães. Disponível em: http://msinstituto.blogspot.com.br/2016/07/joao-guilherme-guimaraes.html Acesso em 12 abr.2018.

MACHADO, Daiane Vaiz O percurso intelectual de uma personalidade curitibana: David Carneiro. Dissertação. Mestrado em História. Curitiba: Universidade Federal do Paraná, 2012.

MANIFESTO - O Partido Democrático Paranaense ao Povo Paranaense. Diário do Paraná, Curitiba, 28.jan.1927, p.3.

MONTEIRO, José Marciano. A Política como negócio de família: os herdeiros e a força dos capitais no jogo político das elites na Paraíba (1985-2015). Tese. Doutorado em Ciências Sociais. Universidade Federal de Campina Grande, 2016.

NEGRÃO, Francisco. Genealogia Paranaense. Curitiba, PR: Imprensa Oficial do Estado do Paraná, 2004. (Volumes I, II, III, IV, V e VI).

NEGRÃO, Francisco. Índice Genealogia Paranaense. Curitiba, PR: Impressora Gráfica Paranaense, 1926. (Volumes I e II).

NICOLAS, Maria. Cem Anos de Vida Parlamentar. Deputados provinciais e estaduais do Paraná. Curitiba: Imprensa Oficial, 1984.

O DIA, Curitiba: 11.11.30, p.5.

O DIA, Curitiba: 24.10.30, capa. 
OLIVEIRA, Ricardo Costa de. Famílias, poder e riqueza: redes políticas no Paraná em 2007. Sociologias [online]. 2007, n.18, pp.150-169.

OLIVEIRA, Ricardo Costa de. O silêncio das genealogias: classe dominante e estado no Paraná (1853-1930). Tese. Doutorado em Sociologia. Universidade Estadual de Campinas, 2000.

PRADO, Maria Lígia Coelho. A democracia ilustrada: O Partido Democrático de São Paulo, 1926-1934. São Paulo: Ática, 1986.

TJ PARANÁ. Des. Benjamin Américo de Freitas Pessoa. Disponível em: https://www.tjpr.jus.br/desembargadores-tjpr-museu/-/asset_publisher/V8xr/content/desbenjamin-americo-de-freitas-pessoa/397262?inheritRedirect=false Acesso em 10 abr.2018

TOURINHO, Luiz Carlos Pereira. Toiro Passante (Volume III: Tempo de República Velha). Curitiba: Gráfica Editora Rocha Ltda, 1990. 